\title{
Synthesis and characterization of soluble poly(ether imide)s based on 2,2'-bis(4-aminophenoxy)-9,9'-spirobifluorene
}

\author{
D. Sahadeva Reddy ${ }^{\mathrm{a}}$, Chia-Hung $\mathrm{Chou}^{\mathrm{a}}$, Ching-Fong Shu ${ }^{\mathrm{a}, *}$, Gene-Hsiang Lee ${ }^{\mathrm{b}}$ \\ ${ }^{a}$ Department of Applied Chemistry, National Chiao Tung University, 1001 Ta Hsueh Road, Hsin-Chu 30035, Taiwan, ROC \\ ${ }^{\mathrm{b}}$ Instrumentation Center, College of Science, National Taiwan University, Taipei, Taiwan, ROC
}

Received 6 September 2002; received in revised form 1 November 2002; accepted 5 November 2002

\begin{abstract}
A series of aromatic poly(ether imide)s containing $9,9^{\prime}$-spirobifluorene moieties in the main chain have been synthesized via the polycondensation of 2,2'-bis(4-aminophenoxy)-9, $9^{\prime}$-spirobifluorene with a variety of aromatic dianhydrides. In the diamine monomer, the two aminophenoxyfluorene entities are orthogonally arranged and are connected through an $\mathrm{sp}^{3}$ carbon atom (the spiro center). The resulting poly(ether imide)s have a polymer backbone which is periodically twisted with an angle of $90^{\circ}$ at each spiro center. This structural feature, which restricts the close packing of the polymer chains and reduces inter-chain interactions, leads to amorphous poly(ether imide)s with good solubility in common organic solvents. In addition, the rigidity of the main chain of these polymers appears to be preserved due to the spiro-structure. As a result, these poly(ether imide)s exhibit a high $T_{\mathrm{g}}$ and excellent thermal stability.
\end{abstract}

(C) 2002 Elsevier Science Ltd. All rights reserved.

Keywords: Organosoluble; Polyimides; Spirobifluorene

\section{Introduction}

Aromatic polyimides possess outstanding thermal, mechanical, and electrical properties, as well as excellent chemical resistance. But their poor processability imposes limitations to their areas of application [1,2]. Therefore, much research effort has been focused on the synthesis of soluble polyimides without deteriorating their otherwise excellent properties [3]. Typical approaches include the introduction of bulky lateral groups [4-9], flexible linkages [10,11], and kinked [12-14] or unsymmetrical structures $[15,16]$ into the polymer backbone.

Previous studies have shown that incorporating a spirobifluorene linkage into the structure of small molecules, as well as polymeric materials, leads to a reduction in crystallization tendency, an enhancement in solubility, and an increase in glass transition temperature [17-25]. In light of these observations, we aimed to synthesize a series of poly(ether imide)s which contain spiro-skeletal units, along with flexible ether linkages, in the polymer main

\footnotetext{
* Corresponding author. Tel.: + 886-35-712121x56544; fax: +886-35723764.

E-mail address: shu@cc.nctu.edu.tw (C.F. Shu).
}

chain, based on a new spiro-fused diamine monomer. The spirobifluorene monomer consists of two identical aminophenoxyfluorene moieties connected through a common tetracoordinate carbon atom (the spiro center). In the spirosegment, the rings of the connected bifluorene entities are orthogonally arranged [17,26,27]. The resulting polyimides would be expected to have a polymer backbone, which is periodically twisted with an angle of $90^{\circ}$ at each spirocenter. This structural feature would restrict the close packing of the polymer chains and reduce the probability of interchain interactions, resulting in high polymer solubility. Furthermore, the main chain rigidity of the polyimide would be preserved due to the spiro-structure, which restricts the free segmental mobility.

Herein, we describe the synthesis of the novel spirofused diamine monomer, 2,2'-bis(4-aminophenoxy)-9, $9^{\prime}$-spirobifluorene (6), starting from 2,2'-dihydroxy-9, $9^{\prime}$-spirobifluorene [28]. This diamine was subjected to polymerization with a variety of aromatic dianhydrides, and the properties of the resulting poly(ether imide)s were studied. These polyimides were found to be highly soluble in common organic solvents and possess good thermal stabilities. 


\section{Experimental section}

\subsection{Materials}

2,2'-Dihydroxy-9, $9^{\prime}$-spirobifluorene (4) was prepared as described in the literature [28]. The dianhydrides $3,3^{\prime}, 4^{\prime} 4^{\prime}-$ biphenyltetracarboxylic dianhydride, 4,4'-oxydiphthalic anhydride, 3,3',4,4'-benzophenonetetracarboxylic dianhydride, and 4,4'-(4,4'-isopropylidenediphenoxy)bis(phthalic anhydride) were recrystallized from acetic anhydride and dried at $150{ }^{\circ} \mathrm{C}$ under reduced pressure prior to use. $4,4^{\prime}$ (hexafluoroisopropylidine)diphthalic anhydride was sublimed before use. $m$-Cresol was freshly distilled under reduced pressure and isoquinoline was used as received.

\subsection{Characterization}

${ }^{1} \mathrm{H}$ and ${ }^{13} \mathrm{C}$ NMR spectra were recorded with a Varian Unity $300 \mathrm{MHz}$ or a Bruker-DRX $300 \mathrm{MHz}$ spectrometer. IR spectra were taken with a Nicolet 360 FT-IR spectrometer. Differential scanning calorimetry (DSC) was performed with a DuPont TA 2000 instrument using a heating/cooling rate of $20{ }^{\circ} \mathrm{C} \mathrm{min}{ }^{-1}$. Samples were scanned from 30 to $400{ }^{\circ} \mathrm{C}$ and then cooled to $30{ }^{\circ} \mathrm{C}$ and scanned for a second time over the same range. The glass transition temperature $\left(T_{\mathrm{g}}\right)$ was determined from the second heating scan. Thermogravimetric analysis (TGA) was made with a DuPont TGA 2950 instrument. The thermal stabilities of all samples were determined in nitrogen by measuring weight loss while heating at a rate of $20{ }^{\circ} \mathrm{C} \mathrm{min}{ }^{-1}$. Mass spectra were obtained with a JEOL JMS-SX/SX 102A mass spectrometer. Gel permeation chromatography (GPC) was carried out with a Waters chromatography connected to a Waters 410 differential refractometer. Three, $5 \mu \mathrm{m}$ Waters styragel columns $\left(300 \times 7.8 \mathrm{~mm}^{2}\right)$ were connected in series and in decreasing order of pore size $\left(10^{5}, 10^{4}\right.$ and $\left.10^{3} \AA\right)$, with DMF as the eluent; PMMA standard samples were used for calibration. Wide-angle X-ray diffraction patterns were obtained at room temperature with a Rigaku XRD-RU $200(\mathrm{Cu} \mathrm{K} \alpha, 40 \mathrm{~mA}, 30 \mathrm{kV})$ at a sampling step of $0.02^{\circ}$ and a scan rate of $5^{\circ} \mathrm{min}^{-1}$. X-ray crystal structure determination was performed with a Bruker SMATER APEX diffractometer using graphite monochromated Mo K $\alpha$ radiation $(\lambda=0.7107 \AA$ ). Structure analyses were performed utilizing the SHELXTL/PC program.

\subsection{2,2'-Bis(4-nitrophenoxy)-9,9'-spirobifluorene (5)}

To a solution of $2,2^{\prime}$-dihydroxy-9, $9^{\prime}$-spirobifluorene (4) $(3.80 \mathrm{~g}, 10.9 \mathrm{mmol})$ in DMF $(15 \mathrm{ml})$ was added potassium carbonate $(4.52 \mathrm{~g}, 33.0 \mathrm{mmol})$ and 4-fluoronitrobenzene $(2.50 \mathrm{ml}, 23.0 \mathrm{mmol})$. The mixture was stirred at $60{ }^{\circ} \mathrm{C}$ for $8 \mathrm{~h}$ under nitrogen. After cooling, the resulting solution was slowly added into $120 \mathrm{ml}$ of water. The precipitated solid was collected by filtration and dried under vacuum. The crude product was recrystallized from acetonitrile to afford crystalline dinitro compound $\mathbf{5}(5.75 \mathrm{~g}, 89.3 \%)$, mp. $191{ }^{\circ} \mathrm{C}$. IR $\left(\mathrm{KBr}, \mathrm{cm}^{-1}\right): 1603,1588,1573,1511,1475,1450,1342$, $1260,1245,1163,1112,871,845,753 .{ }^{1} \mathrm{H}$ NMR (DMSO$\left.d_{6}\right): \delta 6.47(\mathrm{~d}, 2 \mathrm{H}, J=2.0 \mathrm{~Hz}), 6.67(\mathrm{~d}, 2 \mathrm{H}, J=7.5 \mathrm{~Hz})$, $6.98(\mathrm{~d}, 4 \mathrm{H}, J=9.0 \mathrm{~Hz}), 7.15(\mathrm{dd}, 2 \mathrm{H}, J=7.5,7.5 \mathrm{~Hz})$, $7.21(\mathrm{dd}, 2 \mathrm{H}, J=8.3,2.0 \mathrm{~Hz}), 7.41(\mathrm{dd}, 2 \mathrm{H}, J=7.5$, $7.5 \mathrm{~Hz}), 8.00(\mathrm{~d}, 2 \mathrm{H}, J=7.5 \mathrm{~Hz}), 8.10(\mathrm{~d}, 2 \mathrm{H}, J=8.3 \mathrm{~Hz})$, $8.12(\mathrm{~d}, 4 \mathrm{H}, J=9.0 \mathrm{~Hz}) .{ }^{13} \mathrm{C}$ NMR (DMSO-d $): \delta 162.8$, $154.2,150.2,147.8,142.2,140.3,138.7,128.3,128.0$, 126.0, 123.4, 122.4, 120.7, 120.5, 117.1, 115.7, 65.4. HRMS $(\mathrm{m} / z)$ : 590.1478. Calcd 590.1478 for $\mathrm{C}_{37} \mathrm{H}_{22} \mathrm{~N}_{2} \mathrm{O}_{6}$.

\subsection{2,2'-Bis(4-aminophenoxy)-9,9'-spirobifluorene (6)}

A mixture of dinitro compound 5 (4.45 g, $7.54 \mathrm{mmol})$ and $10 \% \mathrm{Pd}-\mathrm{C}(225 \mathrm{mg}, 5 \mathrm{wt} \%)$ in $60 \mathrm{ml}$ of ethanol was stirred under a hydrogen atmosphere for $10 \mathrm{~h}$ at room temperature. The resulting solution was filtered through celite to remove the catalyst and the filtrate was concentrated under reduced pressure to strip off approximately two-thirds of the solvent. On cooling the concentrated solution, white crystalline solid precipitated out. The solid was filtered and dried under vacuum to yield the pure diamine monomer $6(3.31 \mathrm{~g}, 82.8 \%)$, mp: $232{ }^{\circ} \mathrm{C}$. IR ( $\mathrm{KBr}$, $\mathrm{cm}^{-1}$ ): 3457, 3375, 1614, 1578, 1511, 1480, 1455, 1250, $1209,866,830,748,738 .{ }^{1} \mathrm{H}$ NMR (DMSO- $d_{6}$ ): $\delta 4.96$ (br s, $4 \mathrm{H}), 6.07(\mathrm{~d}, 2 \mathrm{H}, J=2.4 \mathrm{~Hz}), 6.48(\mathrm{~d}, 4 \mathrm{H}, J=8.7 \mathrm{~Hz})$, $6.57(\mathrm{~d}, 2 \mathrm{H}, J=7.5 \mathrm{~Hz}), 6.62(\mathrm{~d}, 4 \mathrm{H}, J=8.7 \mathrm{~Hz}), 6.86(\mathrm{dd}$, $2 \mathrm{H}, J=8.4,2.4 \mathrm{~Hz}), 7.06(\mathrm{dd}, 2 \mathrm{H}, J=7.5,7.5 \mathrm{~Hz}), 7.34$ $(\mathrm{dd}, 2 \mathrm{H}, J=7.5,7.5 \mathrm{~Hz}), 7.86(\mathrm{~d}, 2 \mathrm{H}, J=7.5 \mathrm{~Hz}), 7.88(\mathrm{~d}$, $2 \mathrm{H}, J=8.4 \mathrm{~Hz}$ ). ${ }^{13} \mathrm{C}$ NMR (DMSO- $\left.d_{6}\right): \delta 159.0,150.0$, $147.9,145.4,145.3,140.8,135.1,128.0,127.1,123.3$, 121.7, 120.6, 120.0, 116.4, 114.7, 111.5, 65.3. HRMS $(\mathrm{m} / \mathrm{z})$ : 530.1984. Calcd 530.1994 for $\mathrm{C}_{37} \mathrm{H}_{26} \mathrm{~N}_{2} \mathrm{O}_{2}$.

\subsection{Polymerization}

A typical polymerization procedure is as follows. To a solution of $2,2^{\prime}$-bis(4-aminophenoxy)-9,9'-spirobifluorene $(6,265 \mathrm{mg}, 500 \mu \mathrm{mol})$ in $2.5 \mathrm{ml}$ of freshly distilled $\mathrm{m}$ cresol, 4,4'-(hexafluoroisopropylidine)diphthalic anhydride (7a, $222 \mathrm{mg}, 500 \mu \mathrm{mol})$ and isoquinoline (2-3 drops) as a catalyst were added at room temperature and stirred for 30 min under nitrogen atmosphere. The reaction mixture was then stirred at $70-80{ }^{\circ} \mathrm{C}$ for $4 \mathrm{~h}$, and heated to $220^{\circ} \mathrm{C}$, with stirring, for $8 \mathrm{~h}$. After cooling, the viscous solution was added slowly into methanol $(80 \mathrm{ml})$ and the colorless fibrous solid was collected by filtration, washed thoroughly with methanol and dried under vacuum at $100{ }^{\circ} \mathrm{C}$ to afford the corresponding polyimide 8a. The poly(ether imide)s $\mathbf{8 a}-\mathbf{e}$ were further purified by reprecipitating from DMF into methanol several times.

8a: Yield 94\%. IR (KBr, $\left.\mathrm{cm}^{-1}\right): 1779,1726,1598,1480$, 1450, 1374, 1255, 1189, 835, 733. ${ }^{1} \mathrm{H}$ NMR $\left(\mathrm{CDCl}_{3}\right): \delta 6.54$ $(\mathrm{d}, 2 \mathrm{H}, J=2.2 \mathrm{~Hz}), 6.74(\mathrm{~d}, 2 \mathrm{H}, J=7.5 \mathrm{~Hz}), 6.98(\mathrm{~d}, 4 \mathrm{H}$, $J=9.1 \mathrm{~Hz}), 7.03(\mathrm{dd}, 2 \mathrm{H}, J=8.3,2.2 \mathrm{~Hz}), 7.08(\mathrm{dd}, 2 \mathrm{H}$, 
$J=7.5,7.5 \mathrm{~Hz}), 7.26(\mathrm{~d}, 4 \mathrm{H}, J=9.1 \mathrm{~Hz}), 7.33(\mathrm{dd}, 2 \mathrm{H}$, $J=7.5,7.5 \mathrm{~Hz}), 7.76(\mathrm{~d}, 2 \mathrm{H}, J=7.0 \mathrm{~Hz}), 7.78(\mathrm{~d}, 2 \mathrm{H}$, $J=8.3 \mathrm{~Hz}), 7.81(\mathrm{~d}, 2 \mathrm{H}, J=8.8 \mathrm{~Hz}), 7.87(\mathrm{~s}, 2 \mathrm{H}), 7.95(\mathrm{~d}$, $2 \mathrm{H}, J=8.8 \mathrm{~Hz}) .{ }^{13} \mathrm{C} \mathrm{NMR}\left(\mathrm{CDCl}_{3}\right): \delta 166.2,166.0,157.6$, $155.9,150.7,148.3,141.0,139.0,138.0,135.8,132.6$, $132.3,128.0,127.9,125.7,125.3,124.0,123.9,121.1$, 119.8, 119.3, 118.3, 115.9, 65.8.

8b: Yield 93\%. IR (KBr, $\left.\mathrm{cm}^{-1}\right): 1777,1721,1608,1511$, 1475, 1445, 1368, 1260, 1235, 1081, 851, 738. ${ }^{1} \mathrm{H}$ NMR $\left(\mathrm{CDCl}_{3}\right): \delta 1.71(\mathrm{~s}, 6 \mathrm{H}), 6.53(\mathrm{~d}, 2 \mathrm{H}, J=2.1 \mathrm{~Hz}), 6.73(\mathrm{~d}$, $2 \mathrm{H}, J=7.5 \mathrm{~Hz}), 6.93(\mathrm{~d}, 4 \mathrm{H}, J=9.0 \mathrm{~Hz}), 6.97(\mathrm{~d}, 4 \mathrm{H}$, $J=8.8 \mathrm{~Hz}), 7.02(\mathrm{dd}, 2 \mathrm{H}, J=8.4,2.3 \mathrm{~Hz}), 7.07$ (dd, 2H, $J=7.6,7.6 \mathrm{~Hz}), 7.23-7.35(\mathrm{~m}, 14 \mathrm{H}), 7.74-7.78(\mathrm{~m}, 6 \mathrm{H})$. ${ }^{13} \mathrm{C} \mathrm{NMR}\left(\mathrm{CDCl}_{3}\right): \delta 166.8,163.7,157.3,155.9,152.6$, $150.7,148.3,147.5,141.0,138.0,134.2,128.7,128.0$, $127.5,126.0,125.6,125.0,123.9,122.8,121.2,120.0$, 119.9, 119.5, 118.0, 116.0, 111.8, 65.8, 42.5, 31.0.

8c: Yield 95\%. IR (KBr, cm $\left.{ }^{-1}\right): 1777,1726,1603,1486$, $1445,1368,1255,1199,753,722,615 .{ }^{1} \mathrm{H} \mathrm{NMR}\left(\mathrm{CDCl}_{3}\right): \delta$ $6.53(\mathrm{~d}, 2 \mathrm{H}, J=2.1 \mathrm{~Hz}), 6.74(\mathrm{~d}, 2 \mathrm{H}, J=7.6 \mathrm{~Hz}), 6.95(\mathrm{~d}$, $4 \mathrm{H}, J=8.9 \mathrm{~Hz}), 7.02(\mathrm{dd}, 2 \mathrm{H}, J=8.3,2.1 \mathrm{~Hz}), 7.08(\mathrm{dd}$, $2 \mathrm{H}, J=7.5,7.5 \mathrm{~Hz}), 7.26(\mathrm{~d}, 4 \mathrm{H}, J=8.9 \mathrm{~Hz}), 7.30(\mathrm{dd}, 2 \mathrm{H}$, $J=7.8,7.8 \mathrm{~Hz}), 7.37(\mathrm{dd}, 2 \mathrm{H}, J=8.1,2.0 \mathrm{~Hz}), 7.43(\mathrm{~d}, 2 \mathrm{H}$, $J=2.0 \mathrm{~Hz}), 7.75(\mathrm{~d}, 2 \mathrm{H}, J=7.3 \mathrm{~Hz}), 7.77(\mathrm{~d}, 2 \mathrm{H}$, $J=8.3 \mathrm{~Hz}), 7.89(\mathrm{~d}, 2 \mathrm{H}, J=8.1 \mathrm{~Hz}) .{ }^{13} \mathrm{C} \mathrm{NMR}\left(\mathrm{CDCl}_{3}\right)$ : $\delta 166.3,166.2,161.0,157.4,155.9,150.7,148.3,141.0$, $137.9,134.5,128.0,127.9,127.5,127.2,126.1,125.8$, 124.6, 123.9, 121.2, 119.8, 119.4, 118.1, 115.9, 113.9, 65.8.

8d: Yield 94\%. IR (KBr, $\left.\mathrm{cm}^{-1}\right): 1778,1726,1670,1603$, 1511, 1475, 1450, 1373, 1245, 1214, 1158, 1086, 871, 819, 717. ${ }^{1} \mathrm{H} \mathrm{NMR}\left(\mathrm{CDCl}_{3}\right): \delta 6.55(\mathrm{~d}, 2 \mathrm{H}, J=1.8 \mathrm{~Hz}), 6.74(\mathrm{~d}$, $2 \mathrm{H}, J=7.5 \mathrm{~Hz}), 6.93(\mathrm{~d}, 4 \mathrm{H}, J=8.8 \mathrm{~Hz}), 7.03(\mathrm{dd}, 2 \mathrm{H}$, $J=7.9,2.2 \mathrm{~Hz}), 7.08(\mathrm{dd}, 2 \mathrm{H}, J=7.8,7.8 \mathrm{~Hz}), 7.26(\mathrm{~d}, 4 \mathrm{H}$, $J=8.8 \mathrm{~Hz}), 7.33(\mathrm{dd}, 2 \mathrm{H}, J=7.8,7.8 \mathrm{~Hz}), 7.75(\mathrm{~d}, 2 \mathrm{H}$, $J=7.8 \mathrm{~Hz}), 7.77(\mathrm{~d}, 2 \mathrm{H}, J=7.9 \mathrm{~Hz}), 7.95(\mathrm{~d}, 2 \mathrm{H}$, $J=8.0 \mathrm{~Hz}), 8.07(\mathrm{~s}, 2 \mathrm{H}), 8.10(\mathrm{~d}, 2 \mathrm{H}, J=8.0 \mathrm{~Hz}) .{ }^{13} \mathrm{C}$ NMR $\left(\mathrm{CDCl}_{3}\right): \delta 166.1,157.8,155.6,150.7,148.3,141.6$, $141.0,138.1,135.7,135.0,132.1,127.9,127.6,125.4$, 124.5, 123.9, 121.3, 119.9, 117.9, 116.2, 65.8 .

8e: Yield 95\%. IR (KBr, cm $\left.{ }^{-1}\right): 1776,1724,1606,1603$, 1501, 1476, 1446, 1372, 1242, 1204, 1168, 1081, 833, 747. ${ }^{1} \mathrm{H} \mathrm{NMR}\left(\mathrm{CDCl}_{3}\right): \delta 6.55(\mathrm{~s}, 2 \mathrm{H}), 6.74(\mathrm{~d}, 2 \mathrm{H}, J=7.3 \mathrm{~Hz})$, $6.88(\mathrm{~d}, 2 \mathrm{H}, J=6.8 \mathrm{~Hz}), 7.02(\mathrm{~d}, 2 \mathrm{H}, J=7.8 \mathrm{~Hz}), 7.08(\mathrm{dd}$, $2 \mathrm{H}, J=7.8,7.8 \mathrm{~Hz}), 7.23-7.39(\mathrm{~m}, 6 \mathrm{H}), 7.65-7.85(\mathrm{~m}$, $10 \mathrm{H}) .{ }^{13} \mathrm{C} \mathrm{NMR}\left(\mathrm{CDCl}_{3}\right): \delta 166.6,157.8,155.5,150.7$, $148.3,144.5,141.0,138.1,132.7,131.4,128.0,127.6$, $125.5,124.3,124.0,121.8,121.3,119.9,117.6,116.2,65.8$.

\section{Results and discussion}

\subsection{Monomer synthesis}

In order to introduce the spiro-skeletal units into the polyimide backbone, the novel spiro-diamine monomer, 2,2'-bis(4-aminophenoxy)-9, $9^{\prime}$-spirobifluorene (6) was syn- thesized. The precursor, 9,9'-spirobifluorene (1) was prepared by following the Clarkson and Gomberg method, which involves coupling of a Grignard reagent obtained from 2-iodo-biphenyl with 9-fluorene [29], followed by dehydrative ring closure of the resulting carbinol in acetic acid, which on acylation and oxidation, followed by alkaline hydrolysis, afforded the 2,2'-dihydroxy-9,9'-spirobifluorene (4) [28], as shown in Scheme 1. Nucleophilic substitution of 4-fluoronitrobenzene with 4 in $\mathrm{DMF} / \mathrm{K}_{2} \mathrm{CO}_{3}$ medium furnished 2,2'-bis(4-nitrophenoxy)-9, $9^{\prime}$-spirobifluorene (5) in quantitative yields, which on catalytic reduction over $10 \% \mathrm{Pd}-\mathrm{C}$ afforded the desired spiro-diamine monomer 6. The structures of compounds $\mathbf{5}$ and $\mathbf{6}$ were confirmed by IR, ${ }^{1} \mathrm{H}$, and ${ }^{13} \mathrm{C}$ NMR spectroscopy, as well as by mass spectroscopy. The dinitro compound shows characteristic absorptions at 1342 and $1588 \mathrm{~cm}^{-1}$, associated with nitro group stretching, whereas the diamine lacks these two absorption bands. The latter displays new absorptions at 3457, 3375 (N-H stretching) and $1613 \mathrm{~cm}^{-1}(\mathrm{~N}-\mathrm{H}$ deformation). Fig. 1 shows the ${ }^{1} \mathrm{H}$ NMR spectra of compounds 5 and 6 . Based on the reported ${ }^{1} \mathrm{H}$ NMR data of 2,2'-disubstituted-9,9'-spirobifluorene [25] and with auxiliary $2 \mathrm{D}{ }^{1} \mathrm{H}-{ }^{1} \mathrm{H}$ correlation spectroscopy, the positions of the chemical shifts for protons in compounds $\mathbf{5}$ and $\mathbf{6}$ are readily assigned. In the ${ }^{13} \mathrm{C}$ NMR spectra, the central spiro carbon (C-9) signal resonates at $\delta \quad 65.4$ and 65.3, respectively, indicative of the presence of a spiro skeleton in 5 and 6. The molecular structure of compound $\mathbf{5}$ in the solid state was also elucidated by X-ray crystallographic analysis. Single crystals of $\mathbf{5}$ were obtained from acetonitrile solution by slow evaporation of the solvent. Fig. 2 shows the ORTEP plot of $\mathbf{5}$ accomplished by X-ray diffraction at $295 \mathrm{~K}$. The spiro-molecule consists of two identical 4nitrophenoxyfluorene moieties connected through a common tetra coordinate carbon atom (the spiro center). In the spiro-segment, the arrangement of the connected bifluorene entities is nearly orthogonal (dihedral angle $=88.6^{\circ}$ ). This structure agrees with the proposed one.

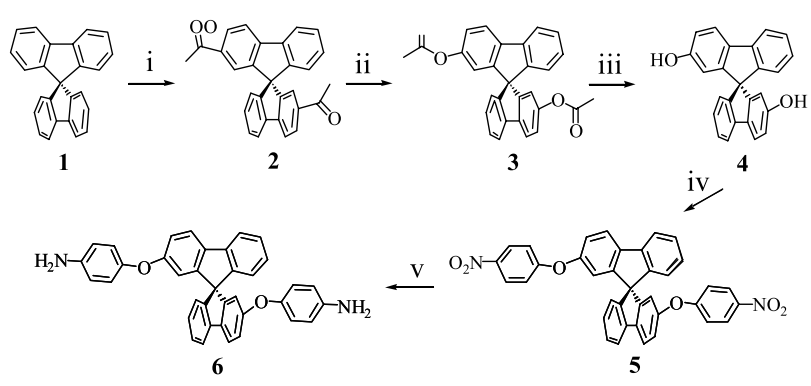

Reagents: (i) $\mathrm{CH}_{3} \mathrm{COCl}, \mathrm{AlCl}_{3} / \mathrm{CS}_{2}$; (ii) $m$-chloroperoxybenzoic acid $/ \mathrm{CHCl}_{3}$;

(iii) $\mathrm{NaOH}(a q) / \mathrm{MeOH}$; (iv) 4-fluoronitrobenzene, $\mathrm{K}_{2} \mathrm{CO}_{3} / \mathrm{DMF}$; (v) $\mathrm{H}_{2}, \mathrm{Pd} / \mathrm{C}$, EtOH

Scheme 1. Reagents: (i) $\mathrm{CH}_{3} \mathrm{COCl}, \mathrm{AlCl}_{3} / \mathrm{CS}_{2}$, (ii) $m$-chloroperoxybenzoic acid/ $\mathrm{CHCl}_{3}$; (iii) $\mathrm{NaOH}(a q) / \mathrm{MeOH}$; (iv) 4-fluoronitrobenzene, $\mathrm{K}_{2} \mathrm{CO}_{3} / \mathrm{DMF}$; (v) $\mathrm{H}_{2}, \mathrm{Pd} / \mathrm{C}$, EtOH. 


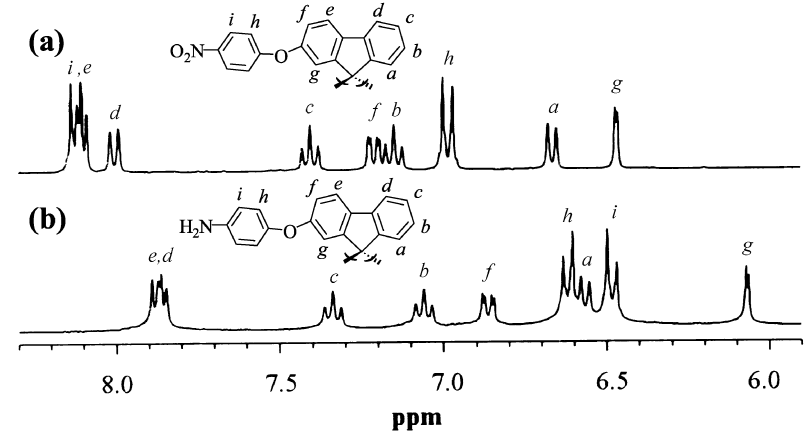

Fig. 1. ${ }^{1} \mathrm{H}$ NMR spectra in the aromatic region of compounds (a) 5 and (b) 6 in DMSO- $d_{6}$.

\subsection{Polymer synthesis}

For the synthesis of poly(ether imide)s $\mathbf{8 a}-\mathbf{e}$, the one-step polymerization method was employed. The one-step method provides some advantages over the conventional two-step method. Polyimides in bulk are more easily produced; further, this method is useful for unreactive diamines and dianhydrides, which cannot form high molecular weight polyamic acids by the twostep method [30]. However, the disadvantage of the one-step method is that insoluble polyimides cannot form high molecular weight polymers because of premature precipitation. We have chosen the one-step solution method, envisaging that the resulting poly(ether imide)s from the 2,2'-bis(4-aminophenoxy)-9, $9^{\prime}$-spirobifluorene (6) could be soluble in $m$-cresol. The spirodiamine and a series of dianhydrides $7 \mathbf{a}-\mathbf{e}$ were reacted in $m$-cresol in the presence of a catalytic amount of isoquinoline (Scheme 2). Fortunately, no premature precipitation was observed during the polymerization. At ambient temperature, after $30 \mathrm{~min}$, a homogeneous and clear solution formed. The temperature was then raised to $70-80{ }^{\circ} \mathrm{C}$, then slowly increased to $220^{\circ} \mathrm{C}$ and maintained there for $8 \mathrm{~h}$. Polymers were isolated in

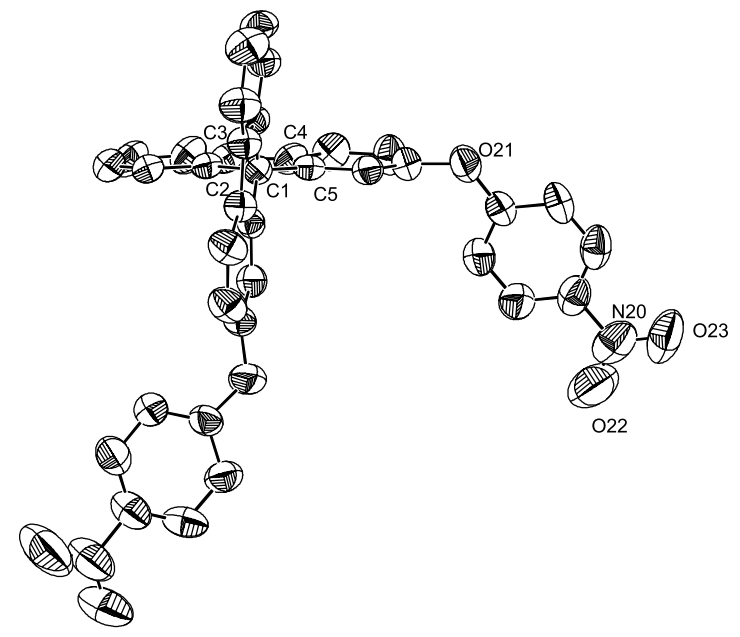

Fig. 2. ORTEP diagram of compound $\mathbf{5}$ determined by X-ray crystallography. All hydrogens are omitted for clarity.
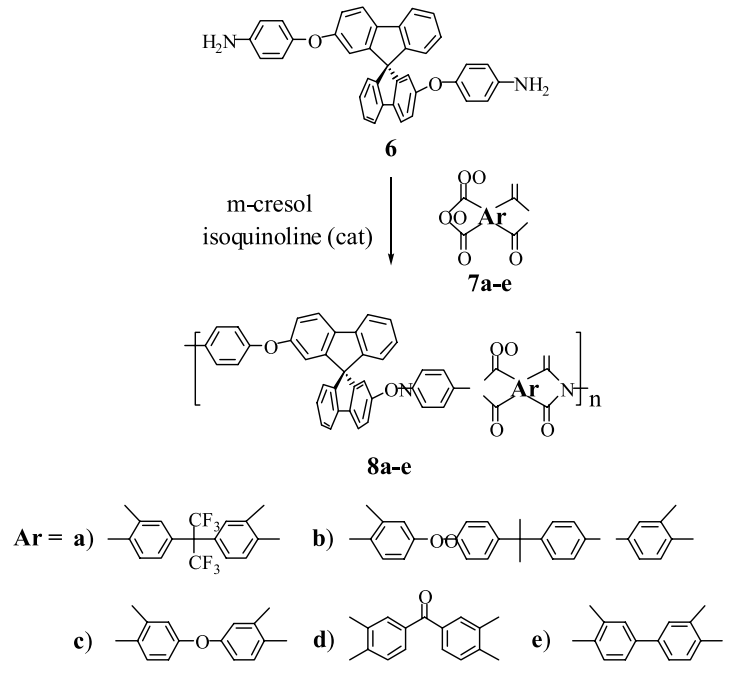

Scheme 2.

quantitative yields by precipitating into methanol and drying under vacuum. In the IR spectra of the obtained polymers, the absence of amic acid absorptions $(\sim 3350$ $(\mathrm{NH}$ and $\mathrm{OH})$ and $1650 \mathrm{~cm}^{-1}$ (amide, $\left.\mathrm{C}=\mathrm{O}\right)$ ) and the presence of cyclic imide carbonyl absorptions (17791776 and $1726-1721 \mathrm{~cm}^{-1}$ ) confirmed the complete cyclodehydration of the corresponding amide intermediate. In addition, DSC and TGA measurements did not show any transition corresponding to imidization, indicating that the resulting polyimides were fully imidized. The structure of the poly(ether imide)s was characterized by ${ }^{1} \mathrm{H}$ NMR. Fig. 3 shows the ${ }^{1} \mathrm{H}$ NMR spectra of polymers $8 \mathbf{a}-\mathbf{e}$. In addition to the distinct features associated with the spirobifluorene diamine component, resonances corresponding to the aromatic protons of the dianhydride component are clearly present. ${ }^{13} \mathrm{C}$ NMR spectra provides complementary information. Resonances associated with the carbonyl carbons of the imide ring appear in the relatively downfield region $(\delta$ 166) [31]. The molecular weights of the polymers were determined by GPC with DMF as the eluent, calibrated against PMMA standards. The molecular weights and polydispersities $\left(M_{\mathrm{w}} / M_{\mathrm{n}}\right)$ are presented in Table 1.

\subsection{Properties of the poly(ether imide)s}

Transparent, flexible films of the poly(ether imide)s can be obtained by solution casting. The crystallinities of the polyimides $\mathbf{8 a}-\mathbf{e}$ were evaluated by wide-angle $\mathrm{X}$-ray diffraction experiments. All the polymers display amorphous diffraction patterns as a result of the presence of the kinked $9,9^{\prime}$-spirobifluorene structure. The amorphous character of the polyimides is also reflected in their high solubility. The solubilities of poly(ether imide)s $\mathbf{8 a}-\mathbf{e}$ were tested in a variety of organic solvents and the results are summarized in 

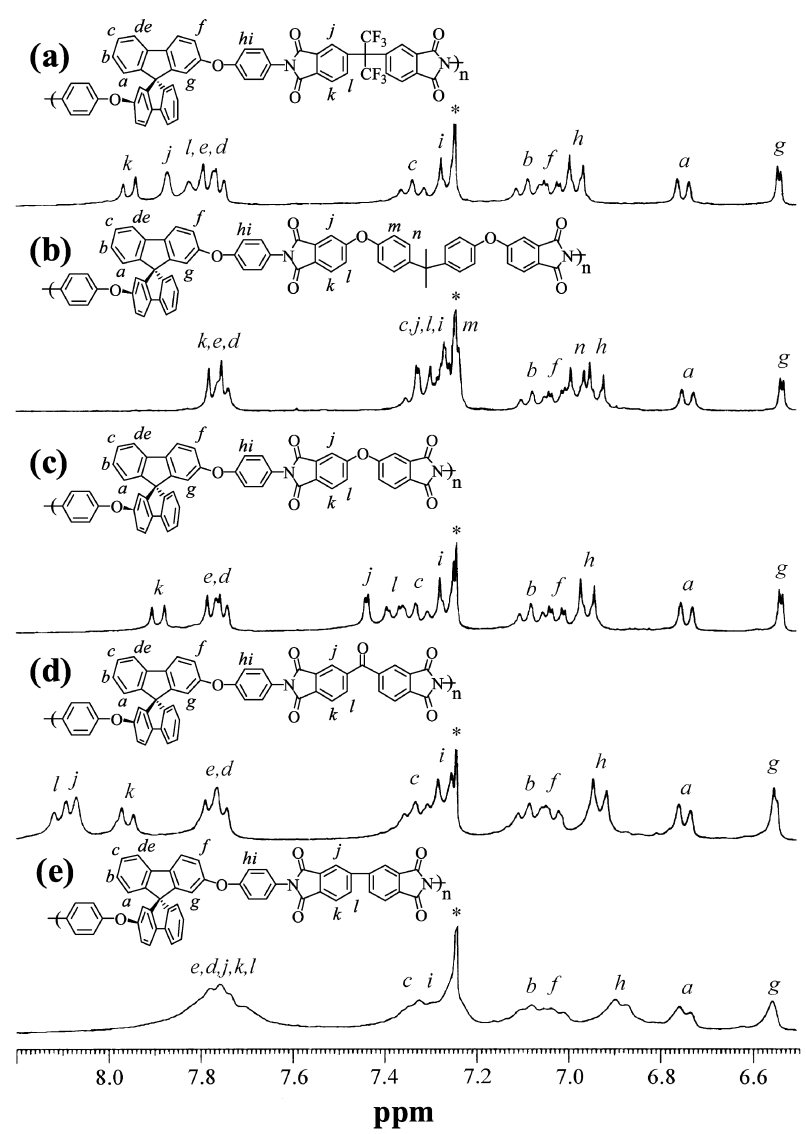

Fig. 3. ${ }^{1} \mathrm{H}$ NMR spectra in $\mathrm{CDCl}_{3}$ of poly(ether imide)s (a) $\mathbf{8 a}$, (b) $\mathbf{8 b}$, (c) $\mathbf{8 c},(\mathrm{d}) \mathbf{8 d}$, and (e) $8 \mathbf{e}$. $*$ indicates a signal arising from $\mathrm{CHCl}_{3}$.

Table 2. All the poly(ether imide)s exhibit good solubility in polar aprotic solvents, such as NMP, DMF, DMAc and pyridine, the phenolic solvent $m$ cresol, as well as chlorinated solvents like chloroform and methylene chloride. The poly(ether imide)s, except polyimide 8e, are also soluble in less polar THF solvent. The poor solubility of $\mathbf{8 e}$ in THF is possibly

Table 1

Molecular weights, inherent viscosities and thermal properties of poly(ether imide)s $8 \mathbf{a}-\mathbf{e}$

\begin{tabular}{lllllllll}
\hline Polymer & $\begin{array}{l}M_{\mathrm{w}}{ }^{\mathrm{a}} \\
\left(\times 10^{4}\right)\end{array}$ & $M_{\mathrm{w}} / M_{\mathrm{n}}$ & $\begin{array}{l}\eta_{\mathrm{inh}}^{\mathrm{b}} \\
(\mathrm{d} 1 / \mathrm{g})\end{array}$ & DSC, $T_{\mathrm{g}} \mathrm{c}$ & $\mathrm{TGA}^{\mathrm{d}}$ & & $\begin{array}{l}Y_{\mathrm{c}} \\
\end{array}$ \\
& & & & & & $T_{5 \%}$ & $T_{10 \%}$ & \\
\hline $\mathbf{8 a}$ & 3.2 & 2.2 & 0.39 & 278 & 564 & 592 & 64 \\
$\mathbf{8 b}$ & 9.4 & 2.0 & 0.75 & 243 & 581 & 590 & 63 \\
$\mathbf{8 c}$ & 4.0 & 2.4 & 0.41 & 279 & 608 & 625 & 69 \\
$\mathbf{8 d}$ & 3.5 & 1.9 & 0.41 & 281 & 581 & 607 & 64 \\
$\mathbf{8 e}$ & 6.0 & 1.9 & 0.55 & 293 & 588 & 616 & 69 \\
\hline
\end{tabular}

${ }^{a}$ Molecular weight $(\mathrm{g} / \mathrm{mol})$ was determined by GPC in DMF based on PMMA standards.

${ }^{\mathrm{b}}$ Measured at $0.5 \mathrm{~g} / \mathrm{dl}$ in DMAc at $30{ }^{\circ} \mathrm{C}$.

${ }^{\mathrm{c}} T_{\mathrm{g}}\left({ }^{\circ} \mathrm{C}\right)$ was determined by DSC at a heating rate of $20^{\circ} \mathrm{C} \mathrm{min}^{-1}$ under nitrogen.

${ }^{\mathrm{d}}$ Temperatures $\left({ }^{\circ} \mathrm{C}\right)$ at which 5 and $10 \%$ weight losses were determined at a heating rate of $20^{\circ} \mathrm{C} \mathrm{min}^{-1}$ under nitrogen.

${ }^{\text {e }}$ Char yield at $900{ }^{\circ} \mathrm{C}$ in nitrogen.

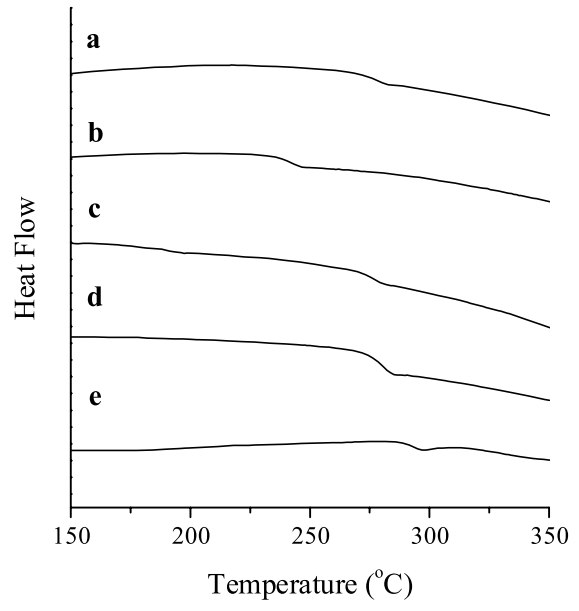

Fig. 4. DSC thermograms of poly(ether imide)s (a) $\mathbf{8 a}$, (b) $\mathbf{8 b}$, (c) $\mathbf{8 c}$, (d) $\mathbf{8 d}$, and (e) $8 \mathbf{e}$.

due to the rigid nature of its dianhydride moiety. The highly soluble nature of these poly(ether imide)s may be attributed to the presence of linked spirobifluorene units, with flexible aryl ether linkages along the polymer backbone. The orthogonally arranged polymer branches would restrict the close packing of the polymer chains and thereby lessen the probability of interchain interactions, resulting in the high solubility of the poly(ether imide)s. It has been demonstrated that the incorporation of a cyclic cardo side group, such as fluorene, into the polymer backbone affords aromatic polyimides high solubility, as well as good thermal stability [32-34]. For comparison, the reported solubility data of fluorenebased cardo poly(ether imide)s 9d and 9e are included in Table 2 [33]. Comparison of polymer solubilities indicates that the $9,9^{\prime}$-spirobifluorene-containing poly(ether imide)s, 8d and $\mathbf{8 e}$, exhibit better solubility than their cardo analogues 9d and 9e. This observation reveals that the placement of the orthogonal arrangement of each bifluorene moiety in the polymer chain plays an important role in enhancing the solubilities of

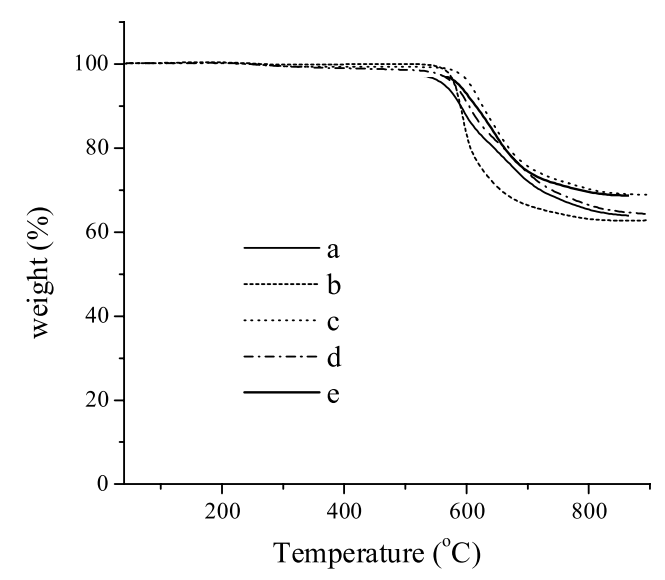

Fig. 5. TGA curves for poly(ether imide)s (a) 8a, (b) $\mathbf{8 b}$, (c) $\mathbf{8 c}$, (d) $8 \mathbf{d}$, and (e) $8 \mathrm{e}$ at a heating rate of $20^{\circ} \mathrm{C} \mathrm{min}^{-1}$ in $\mathrm{N}_{2}$. 
Table 2

Solubility of aromatic poly(ether imide)s

\begin{tabular}{|c|c|c|c|c|c|c|c|c|c|}
\hline \multirow[t]{2}{*}{ Polymer } & \multicolumn{9}{|l|}{ Solvent $^{\mathrm{a}}$} \\
\hline & $\mathrm{CH}_{2} \mathrm{Cl}_{2}$ & $\mathrm{CHCl}_{3}$ & Pyridine & THF & DMF & DMAc & NMP & Acetone & $m$-Cresol \\
\hline $8 \mathbf{a}$ & ++ & ++ & ++ & ++ & ++ & ++ & ++ & -- & ++ \\
\hline $8 b$ & ++ & ++ & ++ & ++ & ++ & ++ & ++ & -- & ++ \\
\hline $8 c$ & ++ & ++ & ++ & ++ & ++ & ++ & ++ & -- & ++ \\
\hline $8 d$ & ++ & ++ & ++ & +- & ++ & ++ & ++ & -- & ++ \\
\hline $9 d^{b}$ & & & -+ & & ++ & -+ & ++ & & -+ \\
\hline $9 e^{b}$ & & & ++ & & +- & -+ & ++ & & -- \\
\hline
\end{tabular}

Solubility: $(++)$ soluble at room temperature; $(+-)$ soluble on heating; $(-+)$ partially soluble or swollen; $(--)$ insoluble.

a $\mathrm{THF}$, tetrahydrofuran; DMF, $N, N$-dimethylformamide; DMAc, $N, N$-dimethylacetamide; NMP, $N$-methyl-2-pyrrolidinone.

b Data from Ref. [33].

the poly(ether imide)s $\mathbf{8 a}-\mathbf{e}$ :

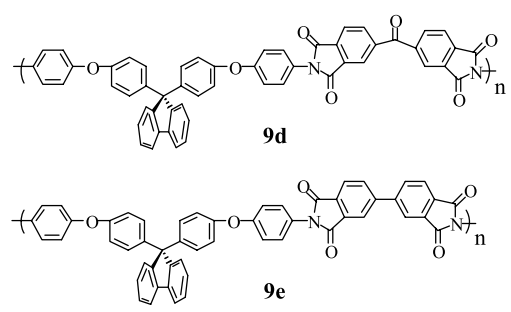

The thermal properties of the poly(ether imide)s were investigated by DSC and TGA, with the results tabulated in Table 1. The incorporation of rigid spirobifluorene units in the polymer backbone results in poly(ether imide)s with high glass transition temperatures $\left(T_{\mathrm{g}}\right)$. Fig. 4 displays DSC thermograms for polymers $8 \mathbf{a}-\mathbf{e}$ The $T_{\mathrm{g}} \mathrm{s}$ of polyimides $\mathbf{8 a}-$ e were in the range of $243-293{ }^{\circ} \mathrm{C}$ and varied with the structure of the dianhydride component. The comparatively lower $T_{\mathrm{g}}$ value of polymer $\mathbf{8 b}$ can be attributed to the presence of a larger number of flexible ether linkages in its polymer chain. Polyimide 8e, containing a stiff biphenyl group, exhibits a higher $T_{\mathrm{g}}$ value. The thermal stabilities of polymers 8a-e were evaluated by TGA. Fig. 5 shows typical TGA curves for these poly(ether imide)s. All the polyimides showed similar patterns of decomposition, without any significant weight loss up to $500{ }^{\circ} \mathrm{C}$ in nitrogen; the residual weights at $800{ }^{\circ} \mathrm{C}$ were all above $60 \%$. Temperatures corresponding with 5 and $10 \%$ weight loss in nitrogen were in the range of 564-608 and 590-625 ${ }^{\circ} \mathrm{C}$, respectively. The high thermal stabilities of these polyimides reflect the rigid nature of spiro-segment unit in the polymer main chain.

\section{Conclusions}

In summary, a new spiro-fused diamine monomer has been synthesized, whose polymerization with various anhydrides leads to highly soluble and thermally stable poly(ether imide)s. The excellent solubility nature of these poly(ether imide)s can be attributed to the presence of spirofused orthogonal bifluorene segments along the polymer chain. High thermal stabilities are due to the rigid spirobifluorene units. Further studies concerning the incorporation of a spirobifluorene unit into the polymer backbone, which may produce novel, soluble and processable high-performance polymeric materials, are in progress.

\section{Acknowledgements}

We thank the National Science Council of the Republic of China for financial support.

\section{References}

[1] Wilson D, Stenzenberger HD, Hergenrother PM, editors. Polyimides. New York: Blackie; 1990.

[2] Mittal KL, editor. Polyimides: synthesis, characterization, and applications, vols. 1/2. New York: Plenum Press; 1984.

[3] de Abajo J, de la Campa JG. In: Kricheldorf HR, editor. Advances in polymer science. Berlin: Springer; 1999. p. 23-59 and references therein.

[4] Lin SH, Li F, Cheng SZD, Harris FW. Macromolecules 1998;31: 2080.

[5] Liaw DJ, Liaw BY, Li LJ, Sillion B, Mercier R, Thiria R, Sekiguchi H. Chem Mater 1998;10:734.

[6] Yang CP, Hsiao SH, Yang HW. Macromol Chem Phys 2000;201:409.

[7] Liaw DJ, Liaw BY, Chung CY. Macromol Chem Phys 2000;201: 1887.

[8] Liou GS, Wang JSB, Tseng ST, Tsiang RCC. J Polym Sci, Part A: Polym Chem 1999;37:1673.

[9] Liaw DJ, Liaw BY, Lai SH. Macromol Chem Phys 2001;202:807.

[10] Eastmond GC, Paprotny J, Irwin RS. Macromolecules 1996;29:1382.

[11] Wang CS, Leu TS. Polymer 2000;41:3581.

[12] Mi Q, Gao L, Ding M. Polymer 1997;38:3663.

[13] Liou GS, Maruyama M, Kakimoto MA, Imai Y. J Polym Sci, Part A: Polym Chem 1998;36:2021.

[14] Matsumoto T, Kurosaki T. Macromolecules 1997;30:993.

[15] Zheng HB, Wang ZY. Macromolecules 2000;33:4310. 
[16] Chung IS, Kim SY. Macromolecules 2000;33:3190.

[17] Salbeck J, Yu N, Bauer J, Weissörtel F, Bestgen H. Synth Met 1997; 91:209.

[18] Salbeck J, Bauer J, Weissörtel F. Macromol Symp 1997;125:121.

[19] Johansson N, dos Santos DA, Guo S, Cornil J, Fahlman M, Salbeck J, Schenk H, Arwin H, Brédas JL, Salenek WR. J Chem Phys 1997;107: 2542.

[20] Kim YH, Shin DC, Kim SH, Ko CH, Yu HS, Chae YS, Kwon SK. Adv Mater 2001;13:1690.

[21] Katsis D, Geng YH, Ou JJ, Culligan SW, Trajkovska A, Chen SH, Rothberg LJ. Chem Mater 2002;14:1332.

[22] Yu WL, Pei J, Huang W, Heeger AJ. Adv Mater 2000;12:828.

[23] Marsitzky D, Murray J, Scott JC, Carter KR. Chem Mater 2001;13: 4285.

[24] Chiang CL, Shu CF. Chem Mater 2002;14:682.

[25] Reddy DS, Shu CF, Wu FI. J Polym Sci, Part A: Polym Chem 2002; 40:262.
[26] Weisburger JH, Weisburger EK, Ray FE. J Am Chem Soc 1950;72: 4250.

[27] Jeffry RW, Schumm S, Pearson DL, Tour JM. J Org Chem 1996;61: 6906.

[28] Prelog V, Bedekovic D. Helv Chim Acta 1979;62:2285.

[29] Clarkson RG, Gomberg M. J Am Chem Soc 1930;52:2881.

[30] Harris FW. In: Wilson D, Stenzenberger HD, Hergenrother PM, editors. Polyimides. New York: Blackie; 1990. p. 1-37.

[31] White DM, Takekoshi T, Williams FJ, Relles HM, Donahue PE, Klopfer HJ, Loucks GR, Manello JS, Matthews RO, Schluenz RW. J Polym Sci, Polym Chem Ed 1981;19:1635.

[32] Korshak VV, Vinogradova SV, Vygodskii YS. J Macromol Sci, Rev Macromol Chem, Part C 1974;11:45.

[33] Yang CP, Lin JH. J Polym Sci, Part A: Polym Chem 1993;31:2153.

[34] Hsiao SH, Li CT. J Polym Sci, Part A: Polym Chem 1999;37:1403. 